\title{
MAGNETIC RESONANCE IMAGING PERFUSION TECHNIQUE IN THE EVALUATION OF ACHILLES TENDON INJURY IN RABBITS
}

\author{
TÉCNICA DE PERFUSÃO À RM NA AVALIAÇÃO DA LESÃO DO \\ TENDÃO DE AQUILES EM COELHOS
}

\author{
Wilson Campos Tavares Junior ${ }^{1}$, Eduardo Paulino ${ }^{2}$, Maria Angélica Baron Magalhaes ${ }^{3}$, Ana Clara Guimarães Gabrich Fonseca ${ }^{2}$, \\ João Bernardo Sancio Rocha Rodrigues ${ }^{1}$, Vivian Resende ${ }^{1}$
}

1. Faculdade de Medicina da Universidade Federal de Minas Gerais (UFMG), Department of Surgery, Belo Horizonte, MG, Brazil.

2. Faculdade de Medicina da Universidade Federal de Minas Gerais (UFMG), Departamento de Anatomia Patológica, Belo Horizonte, MG, Brazil.

3. Faculdade Evangélica do Paraná, Departamento de Cirurgia, Curitiba, PR, Brazil.

\section{ABSTRACT}

Objective: This study aimed to evaluate the dynamic contrast-enhanced magnetic resonance imaging (DCE-MRI) in the experimental model of Achilles tendon injury. Methods: Twelve white male adults New Zealand rabbits were divided into two groups, a group with resection of the central portion of the Achilles tendon $(n=8)$ and a control group $(n=4)$. Dynamic contrast-enhanced magnetic resonance imaging (DCE-MRI) was performed 4 weeks after the surgical procedure, followed by histological analysis of the tendons. Results: The main finding of this study was the difference $(p<0.001)$ in peak contrast enhancement on DCE-MRI, which demonstrated that the operated group had greater contrast uptake. The operated tendons showed histological disruption of their architecture, and cluttered appearance of tendinous fibers, with vascular and fibroblast proliferations. Conclusion: DCE-MRI is a technique with a potential to demonstrate changes in the vascularity pattern of the Achilles tendon before and after operation. DCE-MRI has a potential to be used in studies of tendinosis diagnosis and surgical follow-up. Level of evidence II, Experimental Study.

Keywords: Magnetic Resonance Imaging. Perfusion. Tendon. Wound Healing.

\section{RESUMO}

Objetivos: Avaliar a captação do gadolínio (Gd) à ressonância magnética (DCRM) em modelo experimental de lesão do tendão de Aquiles. Métodos: Foram utilizados 12 coelhos machos, adultos e brancos da raça Nova Zelândia, distribuídos em dois grupos: operados $(n=8)$, com ressecção da porção central do tendão de Aquiles; e o grupo controle $(n=4)$. Após quatro semanas, realizou-se ressonância magnética com técnica de avaliação dinâmica do meio de contraste, seguido de analise histológica dos tendões. Resultados: Houve diferença $(p<0,001)$ do pico máximo de realce de contraste, na DCRM dinâmica do tendão de Aquiles entre os grupos operado e controle, sendo evidenciada maior captação de contraste no grupo operado. À histologia, os tendões operados apresentaram desorganização de sua arquitetura, fibras tendíneas de aspecto desordenado, com neoformação vascular e proliferação de fibroblastos. Conclusão: A DCRM apresentou potencial de demonstrar alterações do padrão de vascularização do tendão de Aquiles no pré e pós-operatório. A DCRM apresenta potencial para ser usada em estudos para controle de tratamento e diagnóstico da tendinose. Nível de evidência II, Estudo Experimental.

Descritores: Imagem por Ressonância Magnética. Perfusão. Tendão. Cicatrização.

Citation: Tavares-Junior WC, Paulino E, Magalhaes MMB, Fonseca ACGG, Rodrigues JBSR, Resende V. Magnetic resonance imaging perfusion technique in the evaluation of achilles tendon injury in rabbits. Acta Ortop Bras. [online]. 2019;27(1):12-5. Available from URL: http://www.scielo.br/aob.

\section{INTRODUCTION}

Magnetic resonance imaging (MRI) is one of the diagnostic methods of choice for evaluation of Achilles tendon (AT) injury. MRI has excellent contrast with soft tissues, high spatial resolution and multiplanar imaging, making it superior to other diagnostic imaging methods to study the anatomy and pathological alterations of AT. The signal changes to the standard MRI without the perfusion technique show little information suggesting the need for additional studies. ${ }^{1,2}$ Dynamic contrast-enhanced magnetic resonance imaging (DCE$\mathrm{MRI})$ is a physiological imaging method that evaluates contrast enhancement kinetics. Images obtained by this method are performed at the stage where the contrast agent is in equilibrium between blood vessels and interstitial spaces. ${ }^{3}$ This technique provides information on tissue vascularization, perfusion, and capillary permeability. DCE-MRI has been used to evaluate various diseases of the musculoskeletal system, tumors ${ }^{3}$ and arthropathies, ${ }^{4,5}$ and it is rare to apply it in the tendon study. ${ }^{6}$

In this context, the objective of this study was to evaluate the feasibility of enhancement in DCE-MRI after experimental injury of the Achilles tendon in rabbits.

All authors declare no potential conflict of interest related to this article.

Study was conducted at the Program of Applied Sciences to Surgery and Ophthalmology of the Faculty of Medicine of UFMG.

Correspondence: Wilson Campos Tavares Junior. Rua Gonçalves Dias, 750, apto 1803, Funcionários, Belo Horizonte, MG, Brasil. 30130091. wilsoncamp2000@yahoo.com.br 


\section{MATERIALS AND METHODS}

This research was approved by the Animal Experimentation Ethics Committee of the Federal University of Minas Gerais (183/2012), adhering to the guidelines established from animal care. Twelve white male New Zealand rabbits (mean weight 2450 grams) were housed individually in stainless steel cages.

\section{Surgical Procedure}

The eight rabbits of the operated group were anesthetized with an intramuscular injection of Xylazine (Calminum, Agener União, Brazil) at the dose of 5-7 mg / kg. After 10-15 min, ketamine (Ketamine Agener 10\%, Agener Union, Brazil) at a dose of $12-15 \mathrm{mg} / \mathrm{kg}$ was injected intramuscularly. During surgery, supplemental sedation was administered when necessary.

The central portion of the Achilles tendon of the right limb was resected measuring $10 \mathrm{~mm}$ in length and $3 \mathrm{~mm}$ in width (Figure 1), which corresponds to approximately one-third the width of the tendon. Four sutures with 5-0 nylon strand were used to identify the parched portion. Then, the tendinous sheath was sutured with PDS 6.0 and, the skin with 3-0 nylon. After the procedure the rabbits were kept inside the cage without immobilization.

\section{Magnetic Ressonance}

After four weeks of surgery, MRI was performed on rabbits using the HDxt Signa GE 1.5 Tesla device (GE Healthcare, Milwaukee, WI, USA). In right lateral decubitus, the right hind limb of the rabbit was positioned in a 9-channel knee coil (1 emitter and 8 receivers). The protocol consisted of a T2-weighted axial and sagittal sequence with fat suppression [RT (repetition time) / TE (echo time): 5000/75 ms; cutting thickness of $2.5 \mathrm{~mm}$; $320 \times 256$ matrix; field of view (FOV), $100 \mathrm{~mm}$; number of excitations (Nex), 2], a T1-weighted sequence, axial plane with FS (TR/TE: 700/15 ms, shear thickness, $2 \mathrm{~mm}, 320 \times 256$ matrix, FOV, $120 \mathrm{~mm}, \mathrm{Nex}, 2)$.

The dynamic series used was 3D SPGR in the axial plane, with 1.2 $\mathrm{mm}$ cutting depth, TR / TE 4/9 ms, flip angle 8 , an acquisition, FOV of 200, 128 of the matrix 128 and TA of acquisition) $20 \mathrm{~s}$. These sequences were composed of 30 cuts, associated with $0.3 \mathrm{mmol} / \mathrm{kg}$ body weight gadopentetate dimeglumine (Magnevist, Schering, Berlin Germany 469mg / ml), injected through a 24 gauge catheter, previously inserted into the ear vein. The contrast agent bolus was injected by injection pump at the rate of $1.5 \mathrm{ml} / \mathrm{sec}$ with the animal into the apparatus. Contrast infusion was initiated immediately after the first sequence of the dynamic series, responding to the non-contrast phase. At the time of contrast infusion, the five

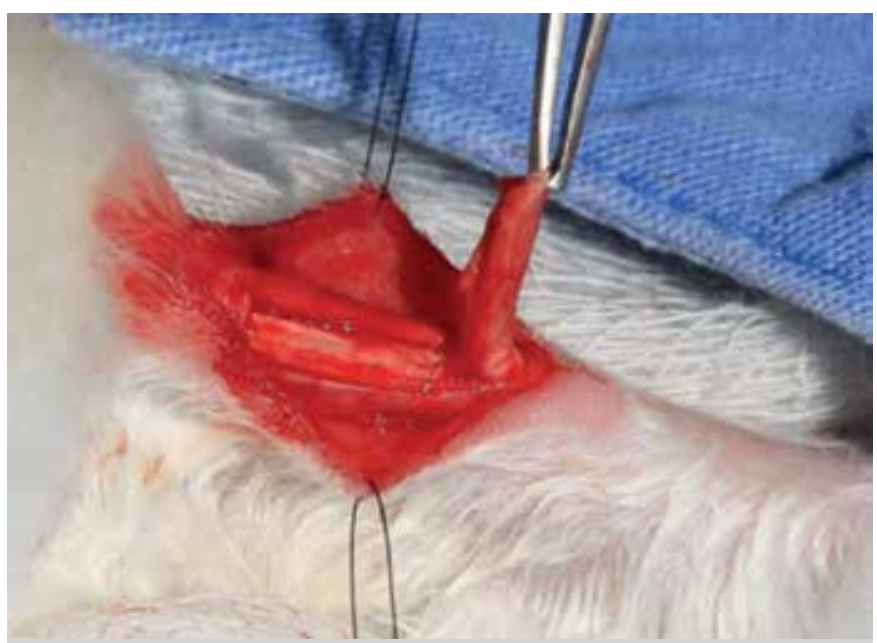

Figure 1. Surgical procedure of the rabbit Aquilles tendon, showing the central segment of the resected Achilles tendon. dynamic sequences without intervals were started. In all animals, dynamic enhancement images were subtracted from the first SPGR sequence, pre-contrast.

\section{Magnetic resonance imaging}

The study was conducted in dedicated General Eletric workstation, ADW 4.6, using specific software for dynamic study Functool.

Contrast enhancement measurements were performed using the region-of-interest (ROI) technique. The $5 \mathrm{~mm}$ diameter $\mathrm{ROI}$ was placed in the Achilles tendon at the same distance from its insertion in the calcaneus, in the region where greater contrast enhancement was observed in the various phases of the DCE-MRI. This evaluation was aided by the contrast capture color map provided by the workstation, with the intention of demonstrating the presence of the contrast and its dynamics of capture, as well as the correlation between the groups, obtaining contrast pick-up curves. The intensity of the enhancement is measured by magnetic resonance unit values, which are given by the workstation. The ROI was also placed in the tibial artery for simple demonstration of the presence of intravenous contrast. All the measurements of the operated and control groups were performed on the axial images and the time-intensity curve, based on the dynamic studies obtained in ROI. In the non-perfusion phase, the middle third of the Achilles tendon was evaluated for intrasubstantial signal intensity, presence of hyperintense foci, and signal heterogeneity. The evaluation was performed by the same experienced radiologist in the musculoskeletal evaluation, without knowledge of the histopathological result (WCTJ).

\section{Histology}

After four weeks of the surgical procedure, the animals were euthanized. The Achilles tendon was completely removed and dissected. Samples were fixed in 10\% buffered formalin solution and embedded in paraffin. The cuts were performed transversally to the longitudinal axis of the tendon. From each tendon, six sections of paraffin were made, stained with hematoxylin-eosin (HE) and submitted to microscopic examination. All sections were analyzed by a single experienced pathologist.

\section{Statistical analysis}

Analysis of variance (ANOVA) was performed and then Fisher's test was used for post-hoc multiple comparisons, when ANOVA revealed a significant difference. The level of significance was set at $p<0.05$.

\section{Results}

In the nonperfusion phase, in the control group (Figure 2), the Achilles tendon was homogeneous and hypointense, with regular and well defined contours in the T1 and T2 sequences without contrast. In the operated rabbits, all tendons showed changes in signal intensity in the weighted T1 and T2 sequences (Figure 3), represented by intrasubstantial hypersignal of irregular and ill-defined contours.

In the control group, in the perfusion phase (Figure 4), there was no significant contrast uptake in the direct observation of the images. The tendon sheath was thin, with no contrast enhancement. The study of the contrast uptake curve showed a slight tendon uptake. In the operated rabbits (Figure 5), in the perfusional sequence, there was tendon enhancement by the contrast medium, which was easily observed in the dynamic sequences or by the color map. The tendon sheath was thickened, with intense contrast enhancement. The contrast uptake curve showed intense enhancement. Comparison of the MRI values obtained by means of the contrast uptake curves showed a significant difference between the values in the control and operated groups ( $p<0.0001)$.

Figure 6 shows the histological appearance of the Achilles tendon in the control (a) and operated (b) groups. In the operated group, we also observed a reduction in the volume of the tendinous portion, diffuse thickening of the sheath, with reduction of adipose tissue and connective-vascular neoformation. 

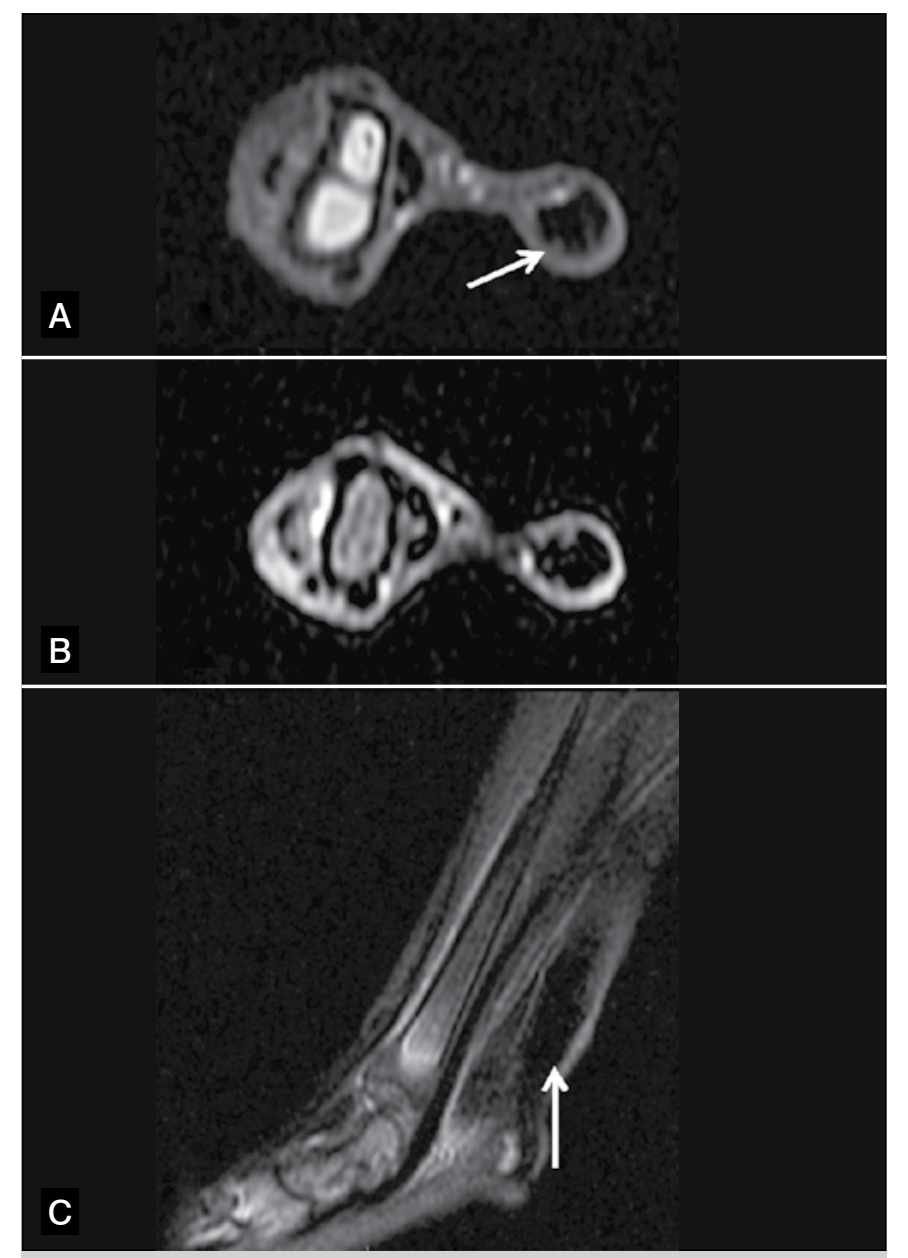

Figure 2. MRI images of Achilles tendon in rabbit of the control group: A) axial cut T1 (white arrow); B) T2 axial cut with fat saturation (corresponding area in a); C) Sagittal cut T2 with fat saturation (white arrow). Observe the homogeneity of the tendon that is diffusely hypointense.

\section{DISCUSSION}

Rabbits have been widely used in research related to the Achilles tendon, however, few studies have evaluated tendon using MRI in rabbits. ${ }^{7,8}$ In the present study, healing was evaluated in the remodeling phase, which usually begins between the second and third week of the cicatricial process. In this way, it would be compatible with the minimum time for beginning the follow-up practiced in the clinical studies that use MRI in the control of treatment of tendinous and ligament injuries. ${ }^{9}$ $\mathrm{MRI}$ of the rabbit Achilles tendon in the axial plane of $2 \mathrm{~mm}$ thickness allowed detailed vision that corresponded to the relationships found in sectional anatomy. Sagittal images of $2 \mathrm{~mm}$ thickness were less useful, which can be explained by the reduced size of tendons and their rotation in relation to the anteroposterior plane.

In this study, we observed a statistically significant difference between the curves resulting from the control and operated groups. This result is probably due to the fact that the normal tendon of the control group does not present significant contrast enhancement because it presents lower vascularization, including in histological studies, which demonstrate that its vascularization is mainly provided by the tendinous sheath. ${ }^{10}$

The main finding of this study was the difference of the maximum peak of contrast enhancement in the dynamic MRI of the Achilles MRD, between the group that underwent the surgical intervention and the control. The mechanism by which contrast enhancement is observed in
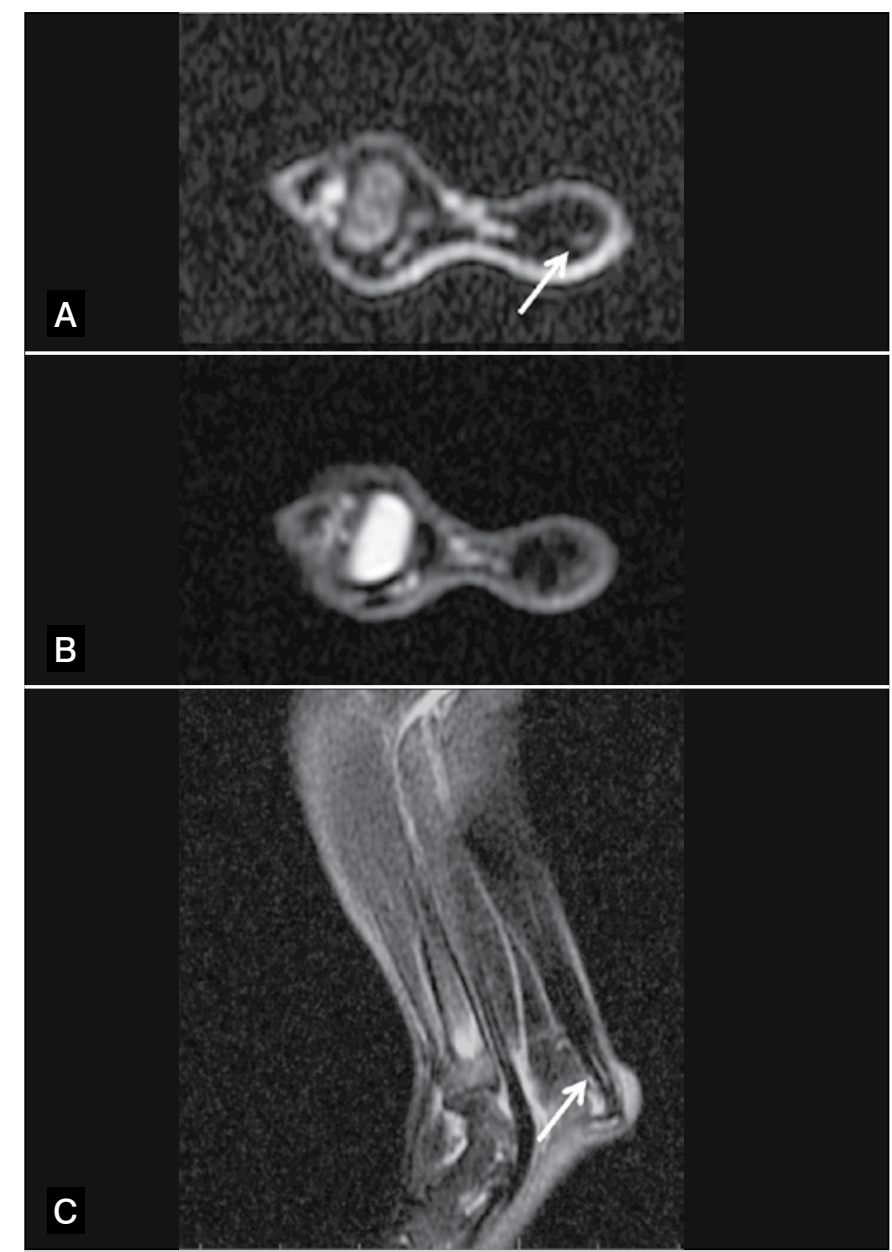

Figure 3. MRI images of the Achilles tendon in rabbit of the operated group: A) axial cut $\mathrm{T} 1$; B) T2 axial cut with fat saturation; C) sagittal cut T2. Observe the heterogeneity of the tendon that presents foci of signal hyperintensity in T1 and T2 (arrows).

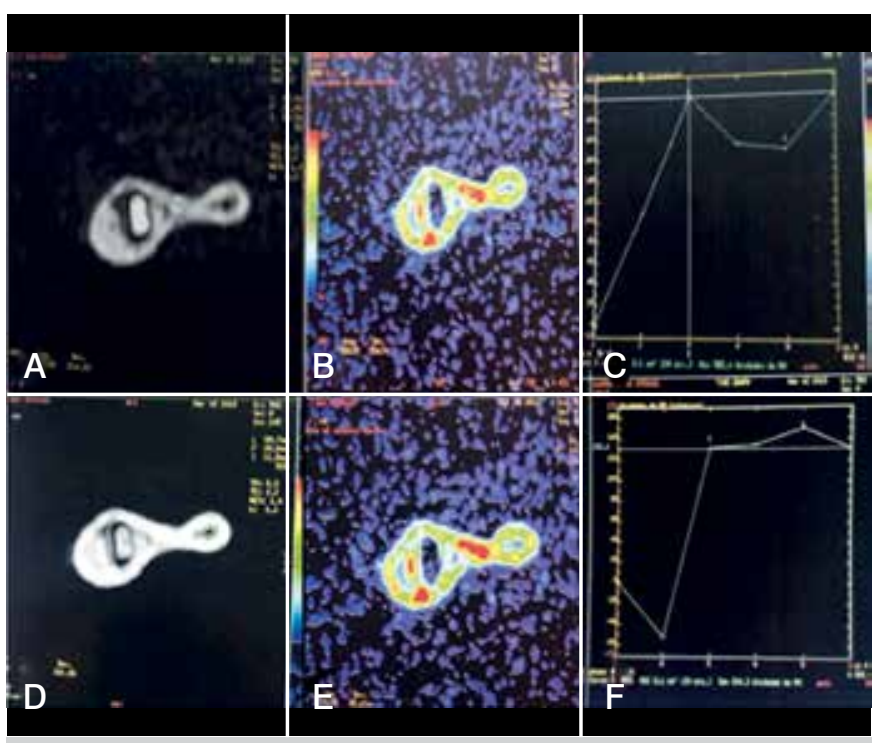

Figure 4. RM in rabbit of the control group: A) ROI within the tibial artery; B) color map showing red areas with maximum contrast gradients; C) curve of contrast uptake in the tibial artery; D) ROI inside the tendon; and. E) color map showing red areas with maximum contrast gradients; F) Contrast capture curve in the tendon. 

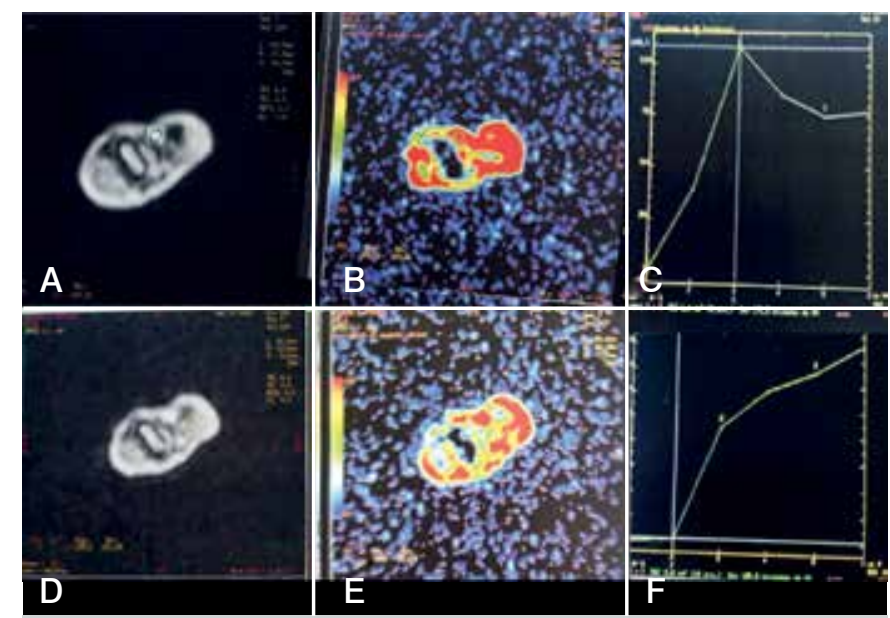

D

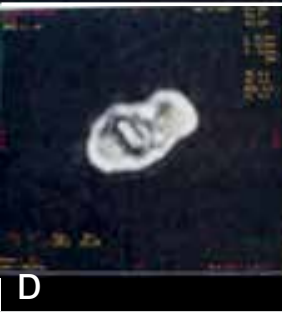

E

Figure 5. RM in rabbit of the operated group: A) ROI within the tibial artery; B) color map showing red areas with maximum contrast gradients; C) curve of contrast uptake in the tibial artery; D) ROI inside the tendon; and. E) color map showing red areas with maximum contrast gradients; F) Contrast capture curve in the tendon.

tendinopathies and in the postoperative period is not fully understood. It is known that the contrast agent initially distributes into the vascular compartment and then diffuses into the extracellular interstice. Increased vascularization and/or vascular permeability may explain the elevation of enhancement in pathological areas, as has been demonstrated in comparative cases of MR imaging with histological analysis. ${ }^{11,12}$

The increase of the extracellular matrix is a frequent finding in the histological evaluation of Achilles tendinopathies. ${ }^{13}$ It is observed a derangement of the collagen fibers, an increase of vascularization and cellularity. ${ }^{14}$ These findings are similar to those found in our experimental study, suggesting that it may help and corroborate the application of DCE-MRI in patients. Studies demonstrate the correlation between areas of maximum pain and maximal hypervascularity in tendons, allowing the use of methods that evaluate tissue vascularization. ${ }^{15,16}$ DCE-MRI is a technique with the potential to demonstrate alterations in the Achilles tendon healing process, evidencing a greater contrast

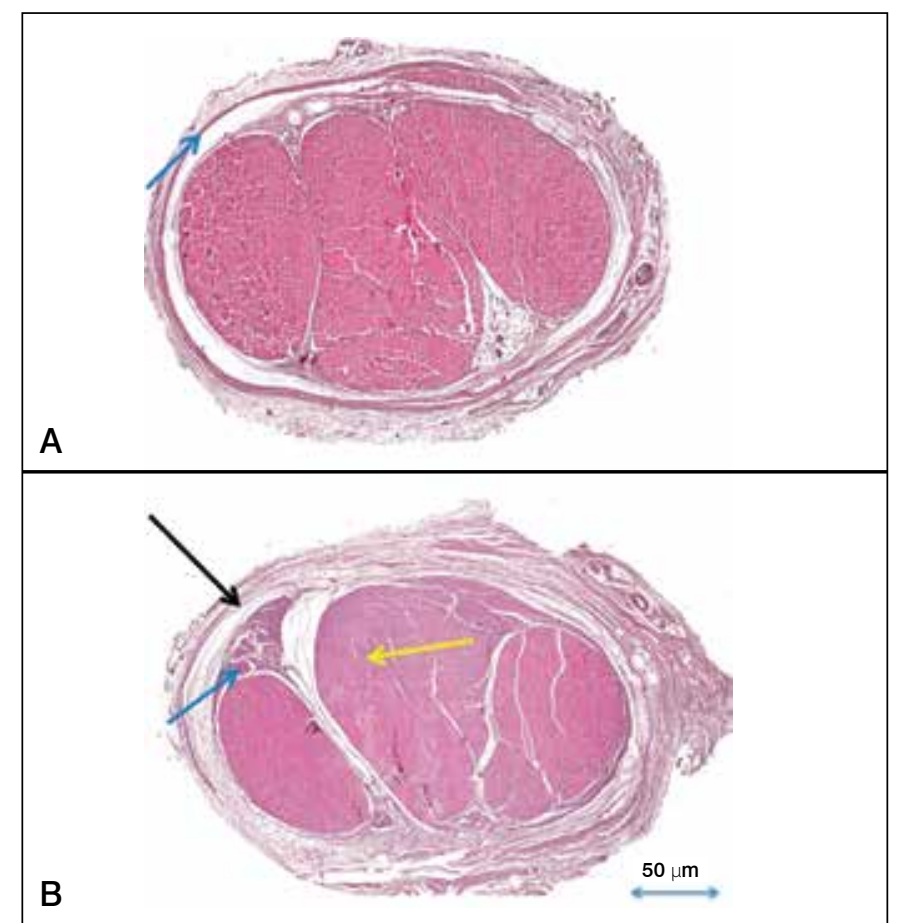

Figure 6. Histological cross section of Achilles tendon in rabbit of the control group (A) and the operated group (B). In (A), preserved architecture is observed, with organized tendon fibers, eosinophilic, sparse vessels and tendinous sheath with thin thickness, homogeneous and organized (arrow); (B), there is a resection area of the tendon with wedge fibrosis (blue arrow) and adjacent tendon with loss of eosinophilia, architectural disorganization (yellow arrow) and thickening of the tendon sheath (black arrow). Haematoxylin-Eosin stain.

enhancement. Our results suggest that this technique could be used in clinical studies to control tendon lesions.

\section{ACKNOWLEDGMENTS}

Radioclinica Itauna for performing MRI.

AUTHORS' CONTRIBUTIONS: All authors contributed individually and significantly to the development of the manuscript. WCTJ (0000-0003-4775-9615)* conducted and interpreted the radiological examinations, revised the bibliography, and drafted the manuscript. MABM (0000-0002-4113-7703) ${ }^{\star}, \mathrm{JBSRR}^{*}$ (0000-0001-8238-5095)* , and ACCGF (0000-0003-4278-3982)* assisted in the surgery, monitored the animals, organized the data, and revised the manuscript. EPJ (0000-0001-6157-6511)* contributed to histopathological studies. VR (0000-0003-4400-0427)* contributed to the study design and review of the manuscript. *ORCID (Open Researcher and Contributor ID).

\section{REFERENCES}

1. Testa V, Maffulli N, Capasso G, Bifulco G. Percutaneous longitudinal tenotomy in chronic Achilles tendonitis. Bull Hosp Jt Dis. 1996;54(4):241-4.

2. Leadbetter WB. Cell-matrix response in tendon injury. Clin Sports Med 1992;11(3):533-78

3. Guo J, Reddick WE, Glass JO, Ji Q, Billups CA, Wu J, et al. Dynamic contrast-enhanced magnetic resonance imaging as a prognostic factor in predicting event-free and overall survival in pediatric patients with osteosarcoma. Cancer. 2012;118(15):3776-85

4. Cimmino MA, Barbieri F, Boesen M, Paparo F, Parodi M, Kubassova O, et al. Dynamic contrast-enhanced magnetic resonance imaging of articular and extraarticular synovial structures of the hands in patients with psoriatic arthritis. J Rheumatol Suppl. 2012;89:44-8.

5. Asakawa DS, Blemker SS, Gold GE, Delp SL. Dynamic magnetic resonance imaging of muscle function after surgery. Skeletal Radiol. 2006;35(12):885-6.

6. Shalabi A, Kristoffersen-Wiberg M, Papadogiannakis N, Aspelin P, Movin T. Dynamic contrast-enhanced $\mathrm{mr}$ imaging and histopathology in chronic achilles tendinosis. A longitudinal MR study of 15 patients. Acta Radiol. 2002;43(2):198-206

7. Seo Y, Ikoma K, Takamiya H, Kusaka Y, Tsoref L, Eliav U, et al. $1 \mathrm{H}$ doublequantum-filtered MR imaging as a new tool for assessment of healing of the ruptured Achilles tendon. Magn Reson Med. 1999;42(5):884-9.

8. Trudel G, Doherty GP, Koike Y, Ramachandran N, Lecompte M, Dinh L, et al. Restoration of strength despite low stress and abnormal imaging after Achilles injury. Med Sci Sports Exerc. 2009;41(11):2009-16.

9. Vogrin M, Rupreht M, Crnjac A, Dinevski D, Krajnc Z, Recnik G. The effect of platelet-derived growth factors on knee stability after anterior cruciate ligament reconstruction: A prospective randomized clinical study. Wien Klin Wochenschr. 2010;122 Suppl 2:91-5.

10. Kvist M, Jozsa L, Jarvinen M. Vascular changes in the ruptured Achilles tendon and paratenon. Int Orthop. 1992;16(4):377-82.

11. Sueyoshi E, Sakamoto I, Uetani M. Myocardial delayed contrast-enhanced MRI: relationships between various enhancing patterns and myocardial diseases. Br J Radiol. 2009;82(980):691-7.

12. Boné B, Wiberg MK, Parrado C, Falkmer U, Aspelin P, Gad A. Mechanism of contrast enhancement in breast lesions at MR imaging. Acta Radiol. 1998;39(5):494-500.

13. Movin T, Gad A, Reinholt FP, Rolf C. Acta Orthop Scand. Tendon pathology in long-standing achillodynia. Biopsy findings in 40 patients. 1997;68(2):170-5.

14. Kaeding C, Best TM. Tendinosis: pathophysiology and nonoperative treatment. Sports Health. 2009;1(4):284-92.

15. Hoksrud A, Ohberg L, Alfredson H, Bahr R. Ultrasound-guided sclerosis of neovessels in painful chronic patellar tendinopathy: a randomized controlled trial. Am J Sports Med. 2006;34(11):1738-46.

16. Khan KM, Bonar F, Desmond PM, Cook JL, Young DA, Visentini PJ, et al. Victorian Institute of Sport Tendon Study Group. Patellar tendinosis (jumper $\square \mathrm{s}$ knee): findings at histopathologic examination, US, and MR imaging. Radiology. Victorian Institute of Sport Tendon Study Group. 1996;200(3):821-7. 